\title{
Congenital Heart Disease in Ugandan Children
}

\author{
JOAN L. CADDELL^ AND D. H. CONNOR
}

From the Departments of Padiatrics and Pathology, Makerere Medical College, Kampala, Uganda, East Africa

The incidence and distribution of congenital heart disease in the tropics and subtropics is not known with certainty. In many regions there is little accurate information on birth and death rates or on the causes of death. However, there is suggestive evidence that the figures from the tropics and subtropics are similar to published figures from the temperate zone. Schrire (1964) in Cape Town found an equal incidence of congenital heart disease in 3 racial groups: white, Capecoloured, and Bantu. Watler (1960) found no difference between the post-mortem incidence and pattern of congenital heart disease in Jamaica and that of other countries. Muir (1960) studied necropsy material largely from the Chinese population in Singapore and noted a remarkable similarity between the cumulative mortality rate of his series and that of other published series. The purpose of this paper is to report the findings of a one-year clinical evaluation of congenital heart disease among Ugandan children seen in the pædiatric service of the New Mulago Hospital, Kampala, Uganda.

\section{SUBJECTS AND METHOD}

All Ugandan children from birth to 12 years of age seen in the newborn nursery, the pædiatric cardiology clinic, or in the pædiatric wards with congenital heart disease were included in the study. A clinical diagnosis was made using routine laboratory tests: electrocardiograms made on a Transrite III Cambridge, battery-run machine, and chest radiographs taken to determine cardiac size and configuration. In a limited number the diagnosis was confirmed at operation (a Blalock procedure on a child with the tetralogy of Fallot, and a ligation of a persistent ductus arteriosus were performed) or at necropsy.

Forty-four children were reviewed. The mean age of the children in the study was $2 \cdot 4$ years; 60 per cent were less than 1 year of age. Eight tribes were represented.

Received December 29, 1965.

* Former Rockefeller Foundation Fellow. This work was supported by the Rockefeller Foundation.

Address: 658 Seneca Avenue, Norwood, Penna. 19074, U.S.A.
RESULTS

Diagnosis. The diagnoses in this small series are listed in the Table. The two most common lesions were ventricular septal defect and persistent ductus arteriosus; other lesions were represented in about the expected proportion, except that the diagnosis of atrial septal defect was not made.

TABLE

CONGENITAL HEART DISEASE IN 44 UGANDAN CHILDREN

\begin{tabular}{l|r}
\hline \multicolumn{1}{c|}{ Diagnosis } & No. \\
\hline Ventricular septal defect & 16 \\
Persistent ductus arteriosus & 12 \\
Atrio-ventricularis communis & 2 \\
Transposition of the great vessels & 2 \\
Pulmonary stenosis & 2 \\
Aortic stenosis & 1 \\
Aortic atresia syndrome & 1 \\
Tricuspid atresia & 1 \\
Tetralogy of Fallot & 1 \\
Single ventricle & 1 \\
Anomalous left coronary artery & 1 \\
Diagnosis uncertain & 4 \\
\hline
\end{tabular}

Two children are of particular interest.

A 5-day-old Muganda boy became severely cyanosed, developed acute respiratory distress, and was admitted to hospital. He had notable right ventricular hypertrophy on the electrocardiogram and X-ray revealed a globular-shaped heart. He died on day 7. Necropsy revealed hypoplasia of the left side of the heart, the aortic valve and the ascending aorta; mitral atresia; and a wide persistent ductus arteriosus.

A 5-month-old Muganda girl was admitted with pneumonia and congestive cardiac failure. Her electrocardiogram (Fig.) showed gross left ventricular hypertrophy. Chest $\mathrm{X}$-ray taken in full inspiration revealed an enlarged heart with a cardio-thoracic ratio of 74 per cent; findings included a prominent pulmonary conus, a double contour at the right heart border, and hazy peripheral lung fields. Despite treatment she became increasingly dyspnœic and died on day 3. Gross examination of the heart performed by Dr. W. C. Manion (1963, personal communication) 


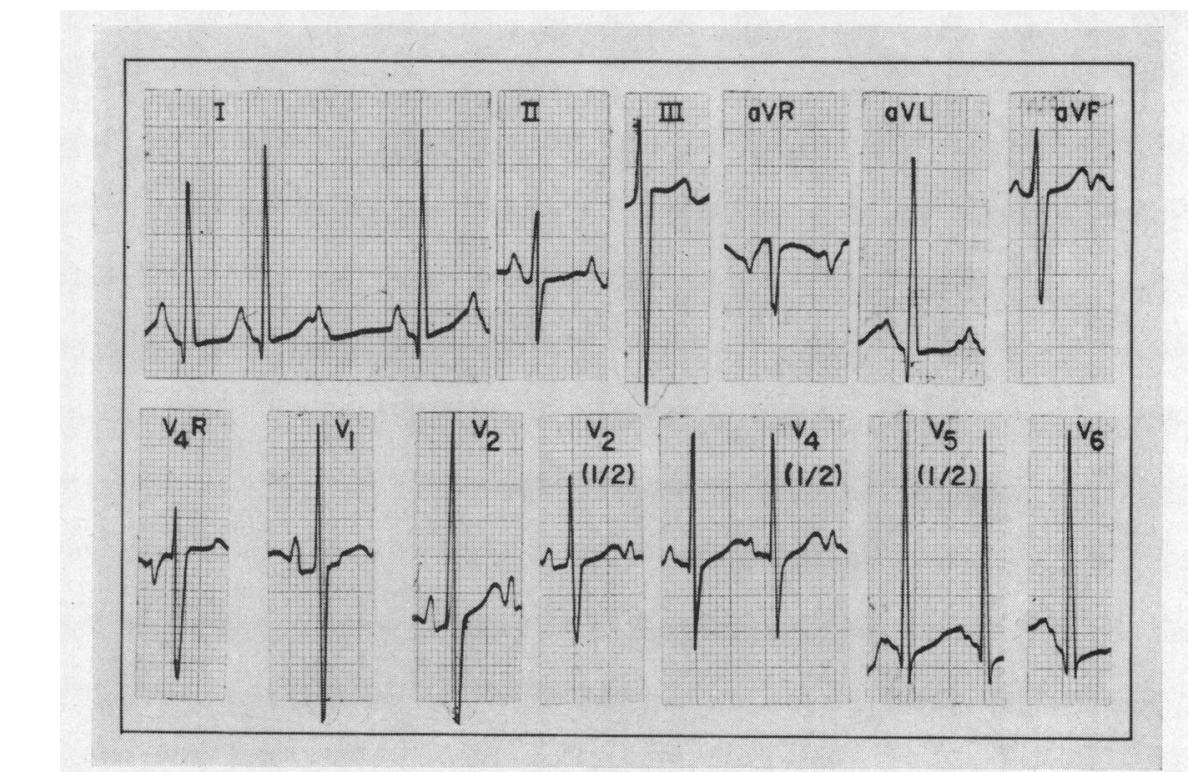

Fig.-Electrocardiogram of a 5-month-old girl with tricuspid atresia. Note the arrhythmia, enlarged $P$ waves, and left ventricular hypertrophy.

revealed Type II(a) of Edward's classification of tricuspid atresia (Keith, Rowe, and Vlad, 1958).

\section{Discussion}

This small series of congenital heart lesions, studied during the first year of a new pædiatric cardiology clinic at the New Mulago Hospital, is almost certainly an under-representation of the true incidence of congenital heart disease among Ugandan children, most of whom are born at home and receive no more sophisticated medical care than is afforded by the rural health clinics. It is believed that many die at home.

This small sample appears to represent a crosssection of congenital cardiac problems, with ventricular septal defect and persistence of the ductus arteriosus heading the list. Atrial septal defects were probably missed, because most children with this lesion are relatively asymptomatic and do not have signs that would be easily detected in the busy pædiatric clinics from which the patients were referred. Rarer lesions were also found and two have been mentioned.

It is concluded that the distribution of congenital cardiac lesions in Ugandan children is probably no different from that of children living in the temperate zone.

\section{SUMMARY}

A brief account of a one-year survey of congenital heart disease among Ugandan children is presented.
There were 44 children, 60 per cent of whom were less than 1 year of age. The mean age was $2 \cdot 4$ years and the sexes were about equally represented. Most of the lesions were found in about the expected numbers except atrial septal defect. It is believed that this relatively asymptomatic lesion may have been missed in rural clinics because of its relatively inconspicuous signs. The distribution of congenital cardiac lesions in Ugandan children is probably no different from that of children living in the temperate zone.

Makerere Professor of Pædiatrics, D.' B. Jelliffe, and Rockefeller Foundation Director, Dr. John M. Weir, encouraged this survey and provided clinical facilities and equipment. Dr. D. H. Wright of the Makerere Department of Pathology generously provided some of the necropsy data. Dr. Grace de Beer, Dr. J. P. Stanfield, and Dr. Arshad Warley gave enthusiastic help by referring patients for study and care.

\section{REFERENCES}

Keith, J. D., Rowe, R. D., and Vlad, P. (1958). Heart Disease in Infancy and Childhood. Macmillan, New York.

Muir, C. S. (1960). Incidence of congenital heart disease in Singapore. Brit. Heart $\mathcal{F}$., 22, 243.

Schrire, V. (1964). The racial incidence of the less common forms of heart disease at Groote Schuur Hospital, Cape Town, 1952-61. S. Afr. med. F., 38, 598.

Watler, D. C. (1960). Congenital heart disease in Jamaica. W. Indian med. F., 9, 194. 